\title{
"Comparative FEM Analysis of V-Shape and Leaf Springs for Improved Suspension with Part Loading Functionality"
}

\author{
T. B. Sonawane ${ }^{1 *}$, S. S. Sarode ${ }^{2}$, M. D. Shende ${ }^{3}$, A. P. Ghodake ${ }^{4}$, D. P. Chavan ${ }^{5}$ \\ ${ }^{I}$ IInd year ME (Design Engg.) Dept. of Mechanical Engg., S.N.D.C.O.E. \& R.C. Yeola, Nashik. \\ ${ }^{2-5}$ Asst. Prof. Dept. of Mechanical Engg., S.N.D.C.O.E. \& R.C. Yeola, Nashik.
}

\begin{abstract}
The Automobile Industry has shown keen interest for replacement of steel leaf spring with that of progressive rate spring unit, since that has good part loading and minor to maximum shock absorption properties. In this paper we have outline on the new mechanism for progressive rate spring. The main leaf spring and $V$ - shape strip spring model is created by modeling software like Pro-E. The dimensions of an existing conventional steel leaf spring of a light commercial vehicle are taken for modeling. And the structural analysis of both springs is carried via finite element analysis using ANSYS-12 software. Result shows that, the $V$-shape strip spring has Total deflection $16.93 \%$ \& Strain energy $38.20 \%$ more than steel leaf Spring for partly loading. It also shows equivalent von- misses stresses for both spring.

It is observed that the $V$ - shape strip spring is great under part loading i.e. minimum loading action and main leaf spring is superior for maximum loading condition so that the whole unit of this progressive rate spring is best suitable for carrying export quality fruit from farm to wear house or customer market and mini ambulance vehicle. All material used in this unit is easily available, so it commercially adopted in automotive mini trailer manufacturer. Also it has less complexity and economically advantageous for middle class farmer.
\end{abstract}

Keywords: Leaf spring, V-shape strip spring, FEA, Part loading, Total deflection, Strain energy.

\section{Introduction:}

Finite Element analysis tools offer the tremendous advantage of enabling design teams to consider virtually any molding option without incurring the expense associated with manufacturing and machine time. The Ability to try new designs or concepts on the computer gives the opportunity to eliminate problems before beginning production.[1] Additionally, designers can quickly and easily determine the sensitivity of specific molding Parameters on the quality and production of the final part. The main leaf spring and V- shape strip spring model is created by modeling software like Pro-E and it is imported in to the analysis software ANSYS12 , the loading, boundary conditions are given to the imported model and result are evaluated by post processor. The different comparative results of main steel leaf spring and V- shape strip spring are obtained to predict the advantages of V- shape strip spring for progressive rate loading for mini trailer which is used in farm for carrying export quality fruit.

\subsection{Introduction Of Structural Analysis:}

Finite Element analysis tools offer the tremendous advantage of enabling design teams to consider virtually any molding option without incurring the expense associated with manufacturing and machine time. The Ability to try new designs or concepts on the computer gives the opportunity to eliminate problems before beginning production. Additionally, designers can quickly and easily determine the sensitivity of specific molding Parameters on the quality and production of the final part. The spring model is created by modeling software like Pro-E, and it is imported in to the analysis software and the loading, boundary conditions are given to the imported model and result are evaluated by post processor.

\section{Fea Procedure (Finite Element Analysis) :}

FEA tool is the mathematical idealization of real system. Is a computer based method that breaks geometry into element and link a series of equation to each, which are then solved simultaneously to evaluate the behavior of the entire system. It is useful for problem with complicated geometry, loading, and material properties where exact analytical solution are difficult to obtain. Most often used for structural, thermal, fluid analysis, but widely applicable for other type of analysis and simulation.[6] Figure 2.1 shows procedure of FEA. 


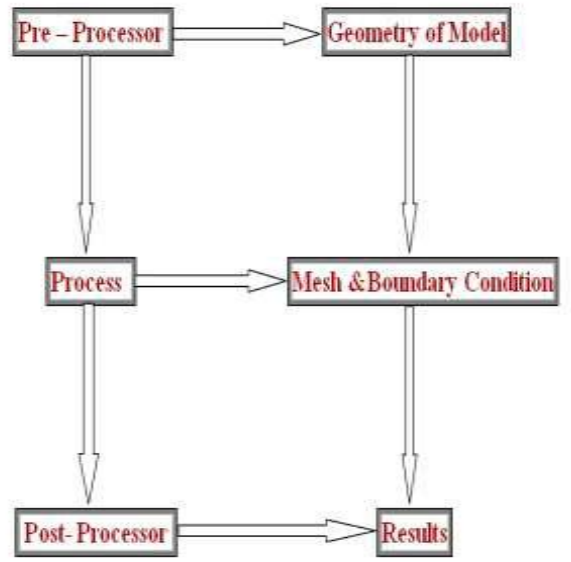

\subsection{Materials For Spring :}

Fig. 2.1 : Typical FEA procedures by commercial software (ANSYS-12)[6]

Plain carbon steel, Chromium vanadium steel, Chromium- Nickel- Molybdenum steel, Silicon manganese steel, are the typical materials that are used in the design of leaf springs. The material selected for steel leaf spring is $65 \mathrm{Si}$. The design parameters selected for steel leaf are listed in table .

\begin{tabular}{|l|l|}
\hline \multicolumn{1}{|c|}{ Parameters } & Values \\
\hline Material selected Steel & $65 \mathrm{Si} 7$ \\
\hline Tensile strength & $1962 \mathrm{~N} / \mathrm{mm} 2$ \\
\hline Yield strength & $1470 \mathrm{~N} / \mathrm{mm} 2$ \\
\hline Young's modulus(E) & $2 \mathrm{e} 5 \mathrm{~N} / \mathrm{mm} 2$ \\
\hline Total length & $650 \mathrm{~mm}$ \\
\hline Arc height at axle seat & $76 \mathrm{~mm}$ \\
\hline Normal static loading (max) & $2500 \mathrm{~N}$ \\
\hline Available space for spring width & $50 \mathrm{~mm} \mathrm{X} \mathrm{6} \mathrm{mm}$ \\
\hline Number of leaves & 02 \\
\hline
\end{tabular}

Table 2.1: Design Parameters of Steel Leaf Spring.[6]

\begin{tabular}{|l|l|}
\hline \multicolumn{1}{|c|}{ Parameters } & \multicolumn{1}{|c|}{ Values } \\
\hline Material selected Steel & $65 \mathrm{Si} 7$ \\
\hline Tensile strength & $1962 \mathrm{~N} / \mathrm{mm} 2$ \\
\hline Yield strength & $1470 \mathrm{~N} / \mathrm{mm} 2$ \\
\hline Young's modulus(E) & $2 \mathrm{e} 5 \mathrm{~N} / \mathrm{mm} 2$ \\
\hline Total length between V end & $100 \mathrm{~mm}$ \\
\hline Included angle of V- shape & $45^{0}$ \\
\hline Normal static loading (max) & $2500 \mathrm{~N}$ \\
\hline Available space for spring width & $30 \mathrm{~mm}$ X $4 \mathrm{~mm}$ \\
\hline Number of strip & 01 \\
\hline
\end{tabular}

Table 2.2: Design Para.eters of Steel V-Shape Strip Spring.

\subsection{Geometry Of Main Leaf Spring \& V-Shape Strip Spring:}

Figure 2.2 shows the imported geometry of mono leaf spring \& figure 2.3 shows the imported geometry of Vshape strip spring. This geometry has been created in Pro-E. Figure shows the 3D model of leaf spring with camber of leaf spring. Total length of mono leaf is $650 \mathrm{~mm}$ and $76 \mathrm{~mm}$ is the arc height at axel seat. 


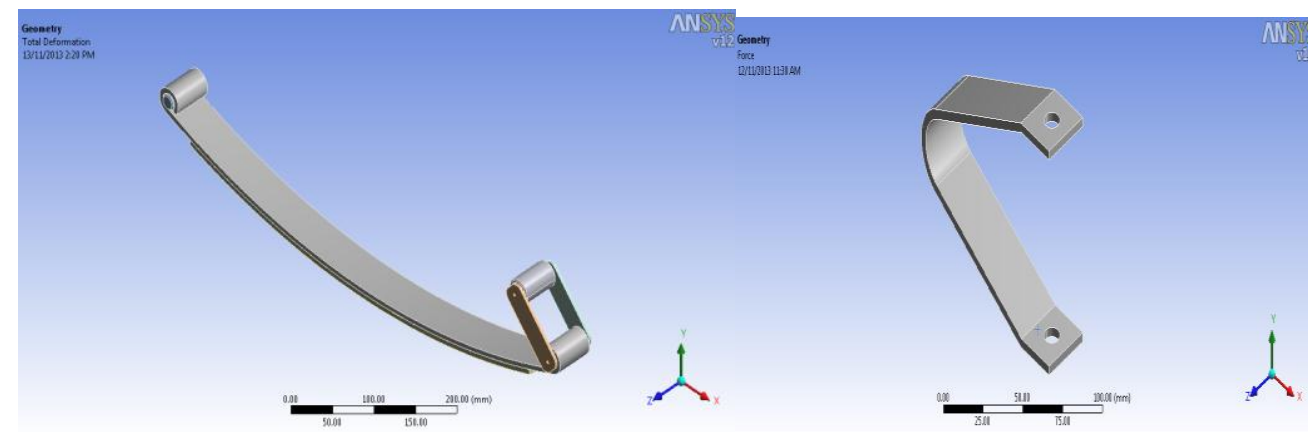

Fig. 2.2: Geometry of Main Leaf Spring.

Fig. 2.3: Geometry of V-Shape Strip Spring.

\subsection{Meshed Model Of Main Leaf Spring \& V-Shape Strip Spring:}

Meshing is nothing but the descritization of object into the small parts called as the element. Figure 2.4 $\&$ figure 2.5 shows the meshed model of both spring with brick and triangular elements are used. Previous Studies show that the best results are obtained using brick mesh.

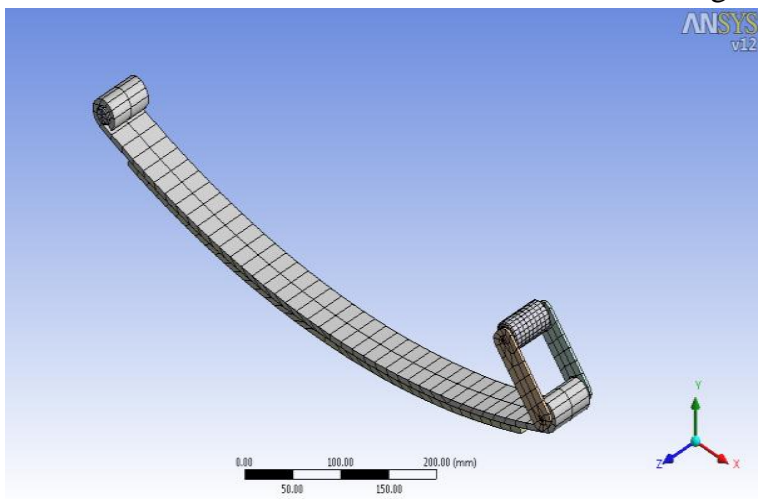

Fig. 2.4: Meshed Model of Main Leaf Spring.

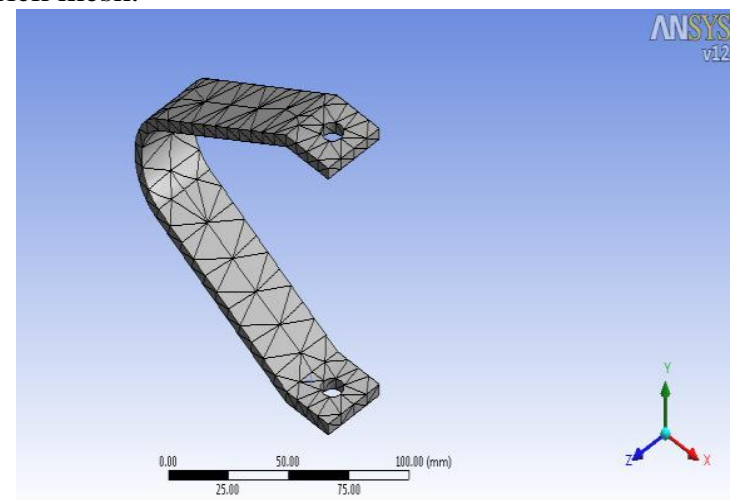

Fig. 2.5: Meshed Model of V-Shape Strip Spring.

\subsection{Loading \& Boundary Conditions Main Leaf Spring \& V-Shape Strip Spring: 2.4.1 Fixed Support:}

Fixed support has restriction to move in $\mathrm{X}$ and $\mathrm{Y}$ direction as well as rotation about that particular point. For the leaf spring analysis one eye end of the leaf spring is fixed to the chassis of the vehicle. So this eye end of the leaf spring cannot move in any of the directions i.e. all the degrees of freedom are blocked. V- shape strip spring expands \& compress in up and down direction so it has no any fixed support but it firmly attached with main leaf spring at up side \& bracket at down side in assembly of whole unit.

\subsubsection{Displacement support:}

As there is shackle provided at other end of the leaf spring because of which the leaf spring only translates in one plane and other movements i.e. degree of freedom are blocked. So with the reference of this a displacement support is applied to the other eye end of leaf spring model. This support allows the movement of the leaf spring in $\mathrm{X}$ axis, rotation about $\mathrm{Z}$ axis and fixed along $\mathrm{Y}$ axis.[6] Also for $\mathrm{V}$-shape strip spring curvature end having free movement in $\mathrm{X} \& \mathrm{Y}$ axis Direction but constant in $\mathrm{Z}$ axis.
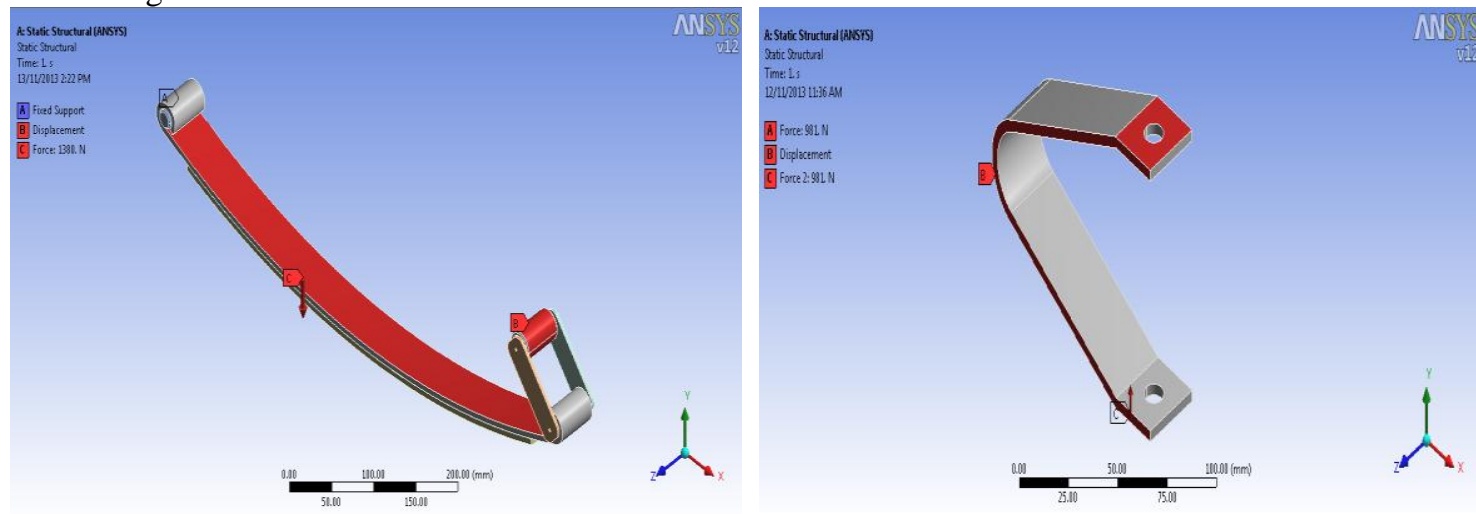

Fig. 2.6 : Loading \& Boundary Conditions of Main Leaf Spring. Fig. 2.7: Loading \& Boundary Conditions of V-Shape Spring. 
Since the load is uniformly distributed on the leaf spring, here in this study uniformly distributed load $1380 \mathrm{~N}$ which is $20 \%$ more of the unladen weight of trailer. For V-shape strip spring it uniformly distributed load $690 \mathrm{~N}$ that is applied on doth side from upward and downward of spring model. The uniformly distributed load is shown in figure 2.6 \& figure 2.7 .

\subsection{Results And Discussion:}

\subsubsection{Total Deflection of Main Leaf Spring \& V-Shape Strip Spring:}

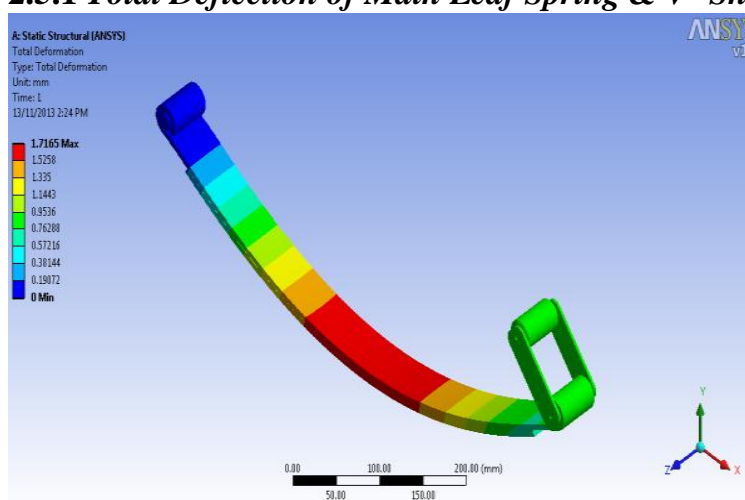

Fig. 2.8: Total Deflection of Main Leaf Spring.

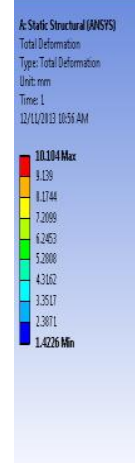

Spring.

Figure 2.8 shows the deflection of steel leaf spring \& Figure 2.9 shows the deflection of steel V- shape strip spring with leaf spring under the application of $1380 \mathrm{~N}$ total load. The maximum deflection is at the centre of the leaf spring is $1.71 \mathrm{~mm}$ and $\mathrm{V}$ - shape strip spring its maximum value is $10.10 \mathrm{~mm}$ from both side. Red zone indicates the area of maximum deflection and blue zone indicates the area of minimum deflection, which are shown by color band. According to this v- shape spring shows the $16.93 \%$ more deflection than leaf spring.

\subsubsection{Stress for Main Leaf Spring \& V-Shape Strip Spring:}

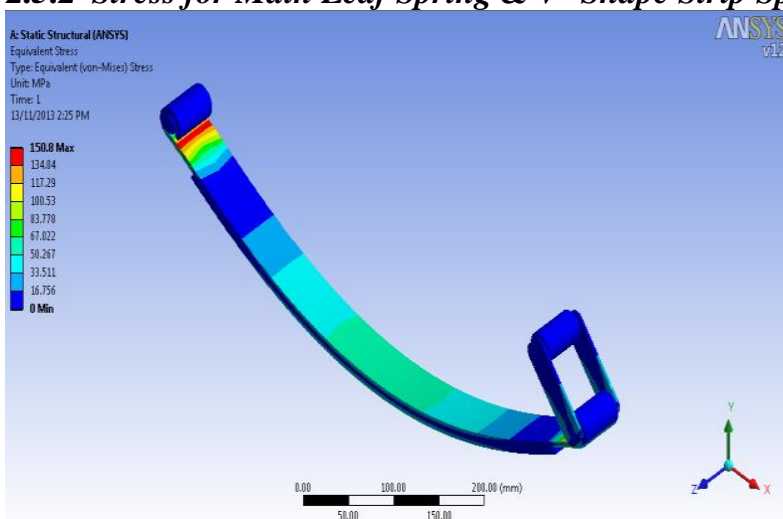

Fig. 2.10: Stress for Main Leaf Spring.

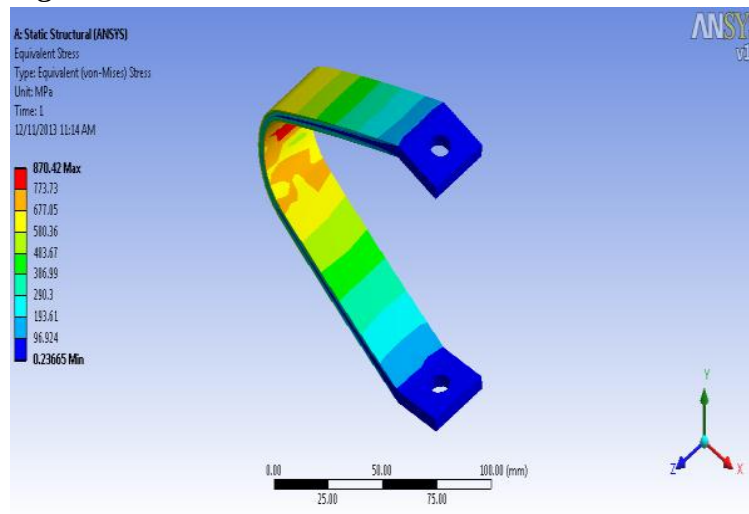

Fig. 2.11: Stress for V-Shape Strip Spring.

Figure 2.10 \& figure 2.11 shows the equivalent von-miss stress induced in steel leaf spring and V-shape strip spring under the action of $1380 \mathrm{~N}$ load. The maximum stress is induced at nearer to fixed eye end of leaf spring and the curvature end of $\mathrm{V}$ - shape strip spring its maximum value is $150.8 \mathrm{~N} / \mathrm{mm}^{2} \& 870.42 \mathrm{~N} / \mathrm{mm}^{2}$ respectively. Red zone indicates the area of maximum stress and blue zone indicates the area of minimum stress.

\subsubsection{Strain Energy for Main Leaf Spring \& V-Shape Strip Spring:}

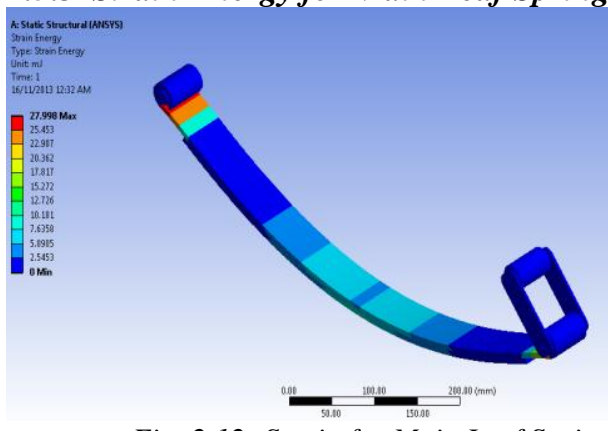

Fig. 2.12: Strain for Main Leaf Spring.
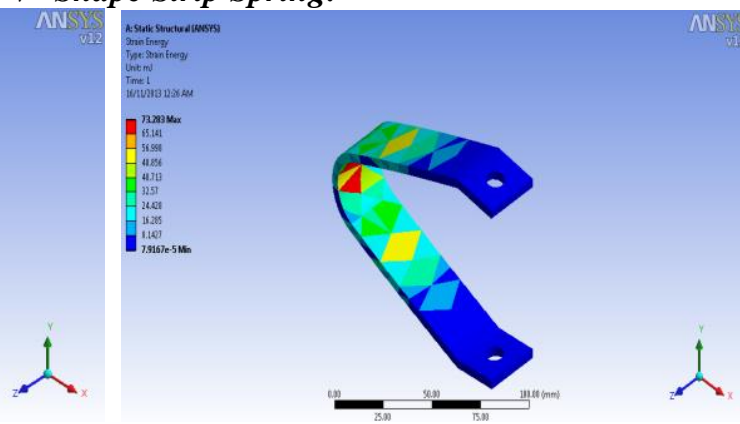

Fig. 2.13: Strain for V-Shape Strip Spring. 
Figure 2.12 \& figure 2.13 shows the strain energy induced in steel leaf spring and V- shape strip spring under the action of $1380 \mathrm{~N}$ load. The maximum strain energy is induced at nearer to fixed eye end of leaf spring and the curvature end of $\mathrm{V}$ - shape strip spring its maximum value is $27.998 \mathrm{MJ} \& 73.283 \mathrm{MJ}$ respectively. Red zone indicates the area of maximum stress and blue zone indicates the area of minimum stress.

\section{Conclusion:}

The 3-D modeling of both steel spring is done and analyzed A comparative study has been made between V- shape strip spring and leaf spring with respect to Total deflection, von-miss stresses and strain energy. From the results, It is observed that the V- shape strip spring shows more deflection i.e $16 \%$ and strain energy $38.20 \%$ than that of steel leaf spring material. It is observed that the $\mathrm{V}$ - shape strip spring is great under part loading i.e. minimum loading action and main leaf spring is superior for maximum loading condition so that the whole unit of this progressive rate spring is best suitable for fruit carrying trailer and mini ambulance vehicle. The $\mathrm{V}$ - spring unit is gradually brought into operation according to the load being applied and progressively increases in proportion to the load being carried and also it is more economical than the conventional steel spring with similar design specifications.

\section{Referance}

[1]. Rajeswaran, Ahamed, Suspension system in automobiles, PHI Learning Private Limited, New Delhi-01, pp. 25-45, 614-625.

[2]. Trailer / Body Builders Journal, on "Trailer Independent Suspension a Huge Success", Australia. October 2000.

[3]. Kristin R. Brandenburg, John R. Keough. Independent Trailer Suspension Utilizing Unique ADI Bracket by Applied Process Inc. Technologies Div. - Livonia, Michigan, USA, 2002.

[4]. Firat Barlas Izmir, on Design of a Mars Rover Suspension Mechanism, Institute of Technology Izmir, Turkey, June 2004.

[5]. Timbren Industries Inc- ID10895 Axle-Less Trailer Suspension, 2010.

[6]. A. P. Ghodake, K.N. Patil "Analysis of Steel and Composite Leaf Spring for Vehicle" IOSR Journal of Mechanical and Civil Engineering (IOSR-JMCE). Volume 5, Issue 4, PP 68-76, Jan. - Feb. 2013.

[7]. A. C. Baviskar, V. G. Bhamre, S. S. Sarode. "Design and Analysis of a Leaf Spring for automobile suspension system: A Review" International Journal of Emerging Technology and Advanced Engineering. Volume 3, Issue 6, June 2013. 